\title{
Pós-Deus: cristianismo e hermenêutica no pensamento de Gianni Vattimo
}

\author{
Post God: \\ christianity and hermenutics in thinking of Gianni \\ Vattimo
}

Paulo Sérgio Lopes Gonçalves Felipe de Queiroz Souto

\section{Resumo}

Objetivamos neste artigo apresentar Deus conforme a designação da hermenêutica niilista de Gianni Vattimo, para superar o Deus da "metafísica objetivista" e designar um movimento de amizade de Deus com a humanidade, presente na convivência fraterna entre os seres humanos. Esse objetivo se justifica no fato de o filósofo italiano propiciar o pensar sobre Deus na pósmodernidade a partir da sentença nietzscheniana da "morte de Deus" e do projeto heideggeriano de "superação da metafísica", trazendo à tona uma concepção de um Deus cristão que emerge da experiência histórica da presença caritativa ou amorosa de Deus na história humana. Para atingir esse objetivo, tomamos algumas obras do mencionado filósofo italiano e apresentamos os conceitos de pensiero debole e de pós-modernidade, expomos a "Idade do Espírito" como uma idade da liberdade, em que o cristianismo se liberta das amarras arbitrárias, dogmatistas e moralistas para ser um cristianismo concentrado na caritas, movimentando-se em torno dela. Em seguida, descrevemos analiticamente o "Deus ornamento", de vertente estética e teor poético, que busca explicitar a sua elevação desde a elevação do humanum.

Palavras-chave: Pós-modernidade. Caritas. Deus. Cristianismo não religioso. 


\begin{abstract}
We aim in this article to present God according to the designation of Gianni Vattimo's nihilist hermeneutics, to overcome the God of "objectivist metaphysics" and to designate a movement of God's friendship with humanity, present in fraternal coexistence among human beings. This objective is justified by the fact that the Italian philosopher proposes to think God in postmodernity from the Nietzschenian sentence of the "death of God" and the Heideggerian project of "overcoming metaphysics", bringing to light a conception of a Christian God that emerges from the historical experience of God's charitable or loving presence in human history. To achieve this goal we take some works of the aforementioned Italian philosopher and present the concepts of pensiero debole and postmodernity, we expose the "Age of the Spirit" as an age of freedom, in which Christianity frees itself from the arbitrary ties, dogmatists and moralists to be a Christianity concentrated on caritas, moving and ... moving around her. Then, to describe analytically the "God ornament", of aesthetic aspect and poetic content, which seeks to explain its elevation since the elevation of the humanum.
\end{abstract}

Keywords: Postmodernity. Caritas. God. Non-religious Christianity.

\title{
Introdução
}

Desde que Nietzsche (1844-1900) formulou a sentença acerca da "morte de Deus", ${ }^{1}$ abriu-se, na filosofia ocidental, a era de uma nova forma de pensar que abandonava os pressupostos sistemáticos da metafísica tradicional e moderna, mesmo as densas construções filosóficas de Kant (1724-1804) e de Hegel (1770-1831). Nietzsche não estava com a preocupação moderna de provar ou não a existência de Deus; pelo contrário, o que movia seu ensejo filosófico era demonstrar que o deus moral ou o deus dos filósofos não fazia mais sentido algum para ser pensado, abrindo o caminho para o pensamento da "desvalorização dos valores supremos", 2 que se resume com a morte do deus ontoteológico. Aqui se encontra um iniciar daquilo que entendemos como o pensamento pós-moderno, em que se inicia uma virada na filosofia que permite que perguntemos: o que há após o Deus que morreu?

${ }^{1}$ NIETZSCHE, F. W., Pere 1882/1895, p. 121-122.

${ }^{2}$ VATTIMO, G., O Fim da Modernidade, p. 4. 
Perguntar-se pelo que há após o "Deus morto" é indagar a história da metafísica em sua condição de história do ser. É com o conceito de ser que trabalha o filósofo italiano, Gianni Vattimo, criticando-o e desenvolvendo-o pelo prisma da hermenêutica. A noção de ser da metafísica clássica está consagrada com a visão parmediana do mundo ocidental e se faz presente no desenvolvimento da filosofia até sua maturação com os modernos ou, ainda, tem sua vigência atualmente na filosofia analítica. Dessa concepção filosófica de mundo, surge aquilo que Nietzsche tratará em seus textos como a doença histórica, que se define como "a impossibilidade de transcender de alguma maneira o processo, quer este tenha ou não um sentido abrangente". ${ }^{3}$ De qualquer modo, o problema de uma razão metafísica que sustenta a realidade por meio do objetivismo é uma questão-chave para o pensamento de Vattimo $\mathrm{e}$, consequentemente, para a composição do pensiero debole.

A ideia de um pensamento que se enfraquece ao libertar-se das premissas metafísicas permite que tenhamos também a noção de um Deus livre de uma visão arquitetônica do universo que dita suas leis e estabelece uma moral rígida. $\mathrm{Na}$ melhor das hipóteses, o pensiero debole liberta Deus de deus e pode, com isso, ser a única filosofia cristã possível, se pensarmos como Vattimo. Isso se afirma na medida em que o cristianismo é a religião do enfraquecimento, da ruptura e do "subsolo". 4

Pensar em um horizonte pós-metafísico ou pós-Deus faz com que surjam questões filosóficas a serem tratadas, a iniciar do prefixo "pós" que merece da nossa parte uma atenção crítica. A concepção de "pós" aparece não como uma superação definitiva, mas como uma chance de transformação ou, ainda, como uma "chance de um novo modo de ser (talvez: finalmente) humanos". 5 Eis o significado da pós-modernidade, da qual inferimos o nosso objetivo neste artigo: apresentar o modo pelo qual a hermenêutica niilista de Gianni Vattimo lê o conceito de Deus do cristianismo na "epocalidade do ser", isto é, atualmente, na "pós-modernidade".

\section{Pensiero debole e pós-modernidade}

A nossa problemática para se pensar o "pós", partícula que também se faz como termo precedente do termo modernidade no mundo contemporâneo, propicia trazer à tona a ideia de que a Pós-modernidade é uma expressão

\footnotetext{
${ }^{3}$ VATTIMO, G., Diálogos com Nietzsche, p. 15.

${ }^{4}$ DE LUBAC, H., O drama do humanismo ateu, p. 321.

${ }^{5}$ VATTIMO, G., A Sociedade Transparente, p. 17.
} 
complexa e até mesmo ambígua à medida que se atribui a ela diversos significados, podendo causar a emergência de outros termos, tais como "modernidade líquida", 6 "hipermodernidade", "modernidade avançada" $\mathrm{e}$ "pós-modernismo". ${ }^{9}$ O filósofo italiano Gianni Vattimo (1936- ) entende que é necessário pensar o tempo presente como pós-modernidade, uma vez que, segundo ele:

O pós de pós-moderno indica, com efeito, uma despedida da modernidade que, na medida em que quer fugir das suas lógicas de desenvolvimento, ou seja, sobretudo da ideia da "superação" crítica em direção a uma nova fundação, busca precisamente o que Nietzsche e Heidegger procuraram em sua peculiar relação "crítica" com o pensamento ocidental. ${ }^{10}$

A superação apontada pelo filósofo provém da crítica feita pelo eixo Nietzsche-Heidegger da qual a história é concebida na modernidade a partir de uma lógica do desenvolvimento progressivo, em que o novo/a novidade é sempre mais interessante e "moderna" já que este "se identifica com o valor através da mediação da recuperação e da apropriação do fundamentoorigem". ${ }^{11}$ A modernidade trouxe consigo novas possibilidades para pensar o ser que o encaixavam nos "sistemas do historicismo metafísico", ${ }^{12}$ pelo qual ainda conservavam uma estabilidade ideal que se dá na história como um desenvolvimento para algo mais novo e verdadeiro que deverá aparecer no fim com o espírito absoluto. É o caso de Hegel, por exemplo, quando afirma em Phänomenologie des Geistes (Fenomenologia do Espírito, 1807/1992) que o "verdadeiro é o todo. No entanto, o todo é somente a essência que se implementa através de seu desenvolvimento. Sobre o absoluto, deve-se dizer que é essencialmente resultado; que só no fim é o que é na verdade". ${ }^{13}$ Por compreender que esse movimento linear da história rumo ao ideal de perfeição ou conformação do indivíduo ao absoluto, Vattimo pondera:

\footnotetext{
${ }^{6}$ BAUMAN, Z., O mal-estar da pós-modernidade.

${ }^{7}$ LIPOVESTKY, G., Tempo contra tempo, ou a sociedade hipermoderna.

${ }^{8}$ GIDDENS, A., As consequências da modernidade.

${ }^{9}$ EAGLETON, T., The usion of postmodernism.

${ }^{10}$ VATTIMO, G., O Fim da Modernidade, p. VII.

${ }^{11}$ VATTIMO, G., O Fim da Modernidade, p. VII.

12 VATTIMO, G., O Fim da Modernidade, p. VIII.

${ }^{13}$ HEGEL, G. W. F., Fenomenologia do Espírito, p. 31.
} 
No entanto, as coisas mudam se, como parece deva-se reconhecer, o pósmoderno se caracterizar não apenas como novidade com relação ao moderno, mas também como dissolução da categoria do novo, como experiência de "fim da história" mais do que apresentação de uma etapa diferente, mais evoluída ou mais retrógrada, não importa, da própria história. ${ }^{14}$

A afirmação de Vattimo sobre a modernidade pode ser compreendida como a operação de passagem do pensamento metafísico do transcendente para uma ontologia que estabelece seu eixo no sujeito dotado de uma razão universal, pela qual conhece e experimenta o mundo. De acordo com Lima Vaz, essa operação possibilita que o homem moderno ocupe "o centro da cena da história e passa [passe] a ser a matriz das concepções contemporâneas do homem que se formularão nos séculos XIX e XX". ${ }^{15}$ Isso é observado no início da modernidade com o Renascimento e as contribuições do filósofo francês René Descartes (1596-1650), que entendia o ser humano como uma dualidade entre corpo e mente, qual favorecia a res cogitans (mente) em detrimento da res extensa (corpo). Aqui, o Cogito ganha um fundamento indubitável e um caráter metafísico que se desenvolverá por toda a modernidade tendo distintas nuances, sobretudo com o sujeito de Kant e com o espírito absoluto de Hegel. Para o Vattimo,

O homem moderno, segundo esta perspectiva, é o homem copernicano, contraposto ao homem ptolomaico: é verdade que este último se punha ao centro do universo, mas a sua posição se sustentava, em última instância, sobre a autoridade do Criador, enquanto o homem copernicano é rotulado a partir do centro, como escreve Nietzsche em um famoso fragmento, porém este centro está vazio, não existe autoridade alguma que seja superior à razão (científica, sobretudo) com a qual o homem, de maneira autônoma, tenta fazer do mundo a sua própria casa. ${ }^{16}$

Na tentativa de pôr fim à metafísica, a modernidade transformou a razão humana em um fundamento metafísico sobre a qual sustentava todas as suas premissas, e tentou fazer dela o centro. Se quisermos levar a cabo um pensamento pós-moderno e enfraquecido, devemos ultrapassar a imposição do cogito e a concepção de uma razão superior e universal. Essa ultrapassagem é

${ }^{14}$ VATTIMO, G., O Fim da Modernidade, p. IX.

${ }^{15}$ LIMA VAZ, H. C., Antropologia Filosófica, p. 79.

16 VATTIMO, G., Depois da Cristandade, p. 91. 
um movimento originado desde a tradição metafísica e deve eclodir para seu exterior em um lento processo de enfraquecimento das estruturas. A ultrapassagem não pode, jamais, ser um processo de superação hegeliana ou de uma criação fantástica ao lado das grandes correntes metafísicas, se fosse assim, retornaríamos ao mito moderno da superação como originalidade do novo, conforme apresentado por Herrera em Supuestos kenóticos del pensamiento débil (2007). ${ }^{17}$ A referida ultrapassagem deve considerar a despedida da lógica moderna tendo em vista uma nova ontologia, teorizada por Vattimo como uma ontologia da atualidade que não "se ocupa de apropriações e reapropriações sucessivas, progressivas e mais aperfeiçoadas do fundamento, mas leva a cabo a negação das estruturas estáveis do ser, considera o seu historiciar-se". ${ }^{18}$

Provém dessas raízes o conceito de Vattimo a respeito do pensiero debole, a nova ontologia que não se apropria da tradição do fundamento, mas pensa o ser na ótica heideggeriana do Abgrund (sem fundamento). ${ }^{19} \mathrm{O}$ pensiero debole recebe a herança moderna como um modo de "vivenciar a verdade, não como o objeto de que nos apropriamos e que transmitimos, mas como horizonte e pano de fundo no qual, discretamente, nos movemos". ${ }^{20}$ Em seu livro Niilismo e pós-modernidade (2005), Rossano Pecoraro entende o pensiero debole sobre cinco traços principais, a saber:

a) A descoberta nietzschiana (e também marxista talvez) do nexo entre evidência metafísica (coatividade do fundamento) e relações de domínio, opressão e poder, dentro e fora do sujeito, deve ser levada muito a sério; $b$ ) isto não quer dizer, porém, que seja necessário, nem sequer útil, precipitarse em novas odisseias especulativas com a elaboração de uma "filosofia da

\footnotetext{
$17 \mathrm{O}$ mito da superioridade insiste na "superioridade do moderno pelo novo (justamente agora), original (apenas aqui), mais avançado (precisamente assim), determinante (imediatamente agora), vinculado ao culto da objetividade perfeita e ao progresso entendido como desenvolvimento histórico linear". Original em espanhol: "superioridad de lo moderno por nuevo (justamente ahora), original (únicamente aquí), más avanzado (precisamente así), determinante (inmediatamente ya), aunado al culto a la objetividad perfecta y al progreso entendido como desarollo histórico lineal" (HERRERA, J. A. R., Supuestos kenóticos del pensamento débil, p. 3).

${ }^{18}$ ROTTERDAN, S.; SENRA, F., O cristianismo não religioso de Gianni Vattimo, p. 99.

19 Em sua obra Vom Wesen des Grundes (HEIDEGGER, M., Wegmarken, p. 123-176), Heidegger aborda a questão do fundamento a partir de seu projeto de "superação da metafísica", afirmando a passagem de Grund para Abgrund, cuja tradução de Vattimo é da passagem de fundamento, tão próprio da metafísica, para sem fundamento, que seria própria da hermenêutica niilista de Vattimo. No entanto, se a tradução de Abgrund for considerada com "abismo", então é possível conceber que a expressão heideggeriana se referia à abertura do aberto mais fundo, o que justificaria o movimento da própria ontologia hermenêutica heideggeriana.

${ }^{20}$ VATTIMO, G., O Fim da Modernidade, p. XX.
} 
emancipação que opere através do desmascaramento e da desmitificação"; c) ao contrário, o caráter decisivo da descoberta, da tomada de consciência, reside justamente na sua capacidade de levar a um mundo novo, e mais amigável, porque menos metafisicamente angustiado, de olhar o mundo das aparências, dos procedimentos discursivos e das formas simbólicas, que é visto, agora, como o "lugar de uma possível experiência do ser"; d) um acontecer, uma experiência do ser, porém, não no sentido de uma "glorificação dos simulacros" (Deleuze) que acabaria por thes doar o mesmo valor e a mesma força do ontos on metafísico, mas no de uma "direção do pensamento capaz de articular (portanto de raciocinar), na meia-luz (segundo um dos verossímeis sentidos de Lichtung de Heidegger); e e) a problemática identificação de ser e linguagem, que a ontologia fraca e a hermenêutica retomam da reflexão heideggeriana, não é uma maneira de retornar ao ser original, verdadeiro, que a metafísica tem esquecido ao longo da sua história e nos seus êxitos tecnológicos e científicos. Não; a identificação, melhor, a conexão cada vez mais estreita entre ser e linguagem é apenas um meio, um caminho "para reencontrar novamente o ser como rastro, lembrança, um ser consumido e enfraquecido (e só por isso digno de atenção)". ${ }^{21}$

As ponderações feitas por Pecoraro deixam clara a perspectiva vattimiana para uma filosofia contemporânea que tende a superação da metafísica para afirmar o caráter violento da metafísica objetivista. ${ }^{22}$ Essa superação não deve ser entendida nos caracteres modernos como se fosse uma "nova odisseia especulativa", mas deve ser tomada como meio para o caminho do ser, assumindo a dinamicidade da linguagem como forma de dizer e redizer o ser. Se fosse o contrário, retornaríamos àquilo que estamos tentando superar: a própria metafísica e sua violência.

$\mathrm{Na}$ perspectiva de sustentar suas premissas filosóficas, Vattimo se estabelece sobre dois autores já pré-anunciados: Nietzsche e Heidegger. Para Nietzsche, a superação da metafísica concentra-se no abandono de todas as pretensões de verdade que sejam eternas, essa concepção abre espaço para o niilismo que vai ser definido pelo filósofo de duas formas: ${ }^{23}$ niilismo ativo e niilismo reativo. $\mathrm{O}$ primeiro fundamenta-se na forma positiva do niilismo pelo qual o mesmo abre a possibilidade de considerar as estruturas do mundo não determinadas, mas passíveis de interpretação dentro de um eterno retorno, uma

${ }^{21}$ PECORARO, R., Niilismo e Pós-modernidade, p. 37.

22 VATTIMO, G., Crer que se crê, p. 37-40.

${ }^{23}$ TEIXEIRA, E., Pós-modernidade e niilismo - um diálogo com Gianni Vattimo, p. 210. 
vez que "não existem fatos, apenas interpretações" 24 que transmutam valores. A segunda perspectiva do niilismo, reativa, refere-se ao fato de que o niilismo pode comportar-se de modo contrário ao processo do cristianismo, ao passo que nega uma natureza metafísica e propõe uma outra inteiramente nova com estruturas objetivamente dadas. Claramente, Nietzsche assume o niilismo ativo como ponto de partida de sua filosofia. $\mathrm{O}$ niilismo aqui "poderia ser definido como o problema da presença do nada ou, ainda, o triunfo do nada na nossa experiência. Aqui se coloca a ausência de fundamento e a falta de certezas, valores e verdades estáveis". ${ }^{25}$ É sobre esses passos que Nietzsche pôde afirmar a sentença da "morte de Deus".

Heidegger, por outro lado, embora influenciado pela filosofia nietzscheana, entende a história da metafísica como "esquecimento do ser", isto é, a compreensão de que a metafísica se esqueceu - "não dissolveu[-se] nem desapareceu[-se]"26 - do problema do ser e se empenhou por privilegiar o ente, principalmente o ente supremo, abrindo a possibilidade de uma ontologia a partir do "sendo". Resulta, então, um projeto de ontologia hermenêutica, em que se busca restabelecer a problemática do ser na filosofia contemporânea de modo aberto, pois o compreende na relação com o Dasein que está jogado às vivências pelas quais ele apreende e compreende o mundo e a si mesmo na lógica da Geworfenheit heideggeriana. Dessa forma, a "aparição" do ser se dá na "Ereignis - traduzida por acontecimento-apropriação ou como evento em que o ser se dá ao homem na forma de destino - Geschick - e transmissão - Überlieferung - evidenciando, desse modo, um caráter epocal do ser". ${ }^{27}$

Nietzsche e Heidegger compreendem a necessidade da filosofia em superar a metafísica sem a concepção moderna e antropocêntrica. Vattimo os interpreta como autores que se coincidem na tarefa filosófica ao relacionar a "morte de Deus" e a "eventualidade do ser" como modos de compreender o processo do "pensamento ultrametafísico". No entanto, enquanto para Nietzsche há uma desvalorização dos valores, para Heidegger há uma redução do ser ao valor. Tem-se, portanto, a necessidade de compreender esse valor como valor de troca; assim, os valores que devem ser destituídos em Nietzsche são os valores supremos que assumem o seu máximo grau em Deus. Desse modo, "somente onde não há instância terminal e 'interruptiva', bloqueadora, do valor supremo-Deus, os valores podem manifestar-se em sua verdadeira

\footnotetext{
${ }^{24}$ NIETZSCHE apud VATTIMO, G., A Idade da Interpretação, p. 61.

${ }^{25}$ TEIXEIRA, E., Pós-modernidade e niilismo - um diálogo com Gianni Vattimo, p. 211.

${ }^{26}$ VATTIMO, G., O Fim da Modernidade, p. 4.

${ }^{27}$ GONÇALVES, P. S. L., A evocação do pensiero debole na Teologia da Libertação, p. 248.
} 
natureza, que é a convertibilidade, e a transformabilidade/ processualidade indefinida". ${ }^{28}$ Portanto, mesmo em Nietzsche, pode-se dizer que os valores existem segundo a lógica vattimiana, mas podem ser trocados indefiníveis vezes dentro de um eixo niilista, que é a "consumação do valor de uso no valor de troca". O niilismo é a dissolução completa do ser no "dis-correr do valor, nas transformações indefinidas da equivalência universal". ${ }^{29}$

Eis o pensamento nevrálgico que culminará na superação da metafísica e aqui cabe a delimitação do conceito de superação: para Vattimo, houve a pretensão de se superar a metafísica com a ciência moderna e a posteridade da filosofia nietzscheana. No entanto, segundo a perspectiva heideggeriana, essa superação que seria uma Überwindung (aquisição da veracidade e descarte do falso) foi, na realidade, uma Verwindung, algo que, em suas próprias palavras, é como "uma longa convalescença que tem de tornar a enfrentar o vestígio indelével de sua doença" ${ }^{30}$ ou, ainda, aquela que estabelece uma relação "de aceitação, de continuação, de (dis-)torção" com a metafísica. ${ }^{31}$ Desse modo, o problema da metafísica não foi algo superado por inteiro, mas é algo que permanece e retorna nas discussões filosóficas de nosso tempo. Vattimo equivale a "presença convalescente" da metafísica no pensamento hodierno ao retorno da religião na contemporaneidade, entendendo que o discurso da "morte de Deus" não encerra nem a possibilidade nem a legitimidade da religião, mas "assinala e abre um percurso marcado por uma nova e renovada vitalidade da experiência religiosa dentro da pós-modernidade", ${ }^{32}$ com todo seu caráter paradoxal, em que se tem simultaneamente a emergência da Ge-Stell e da fábula, do clamor pela identidade singular e do pluralismo, da secularização do sacro e retorno ao religioso.

\section{Deus na Idade do Espírito}

O pluralismo tardo-moderno permitiu as inúmeras compreensões religiosas, fazendo-se necessário um pensamento enfraquecido que considera o ser fora das estruturas objetivistas. Influenciado pelo pensamento hermenêutico de Luigi Pareyson (1918-91) e Hans-Georg Gadamer (1900-2002), tendo sido esses seus professores, sem perder as esteiras de Nietzsche e Heidegger, Vattimo

\footnotetext{
${ }^{28}$ VATTIMO, G., O Fim da Modernidade, p. 6.

${ }^{29}$ VATTIMO, G., O Fim da Modernidade, p. 6.

${ }^{30}$ VATTIMO, G., O vestígio do vestígio, p. 91.

31 VATTIMO, G., Para Além Da Interpretação, p. 81.

32 PECORARO, R., Niilismo e Pós-modernidade, p. 123.
} 
inicia na hermenêutica a tendência niilista e passa a pensar o problema do ser e o problema de Deus dentro do eixo da hermenêutica niilista, que é também uma ontologia enfraquecida, que "nada mais é que interpretação da nossa condição ou situação, já que o ser não é nada fora do seu 'evento', que acontece no seu e nosso historicizar-se". ${ }^{33}$ Em sua obra Dopo la cristianità (Depois da Cristandade, 2002/2004), o filósofo de Turim estabelece uma relação com o monge cisterciense medieval, Gioacchino de Fiore (1135-1202) - que postulou em seus escritos o advento da Idade do Espírito Santo, permitindo que ocorra um "momento de ruptura" ${ }^{34}$ na história da religião a partir de seu pensamento - e sua ontologia hermenêutica. No entanto, para nos situarmos na compreensão de Fiore, temos: a humanidade transcorreu o tempo do Pai, marcado pelo temor, posteriormente o do Filho, marcado pela fé, e o que se aproximava, em sua visão profética, era o tempo do Espírito, que será marcado pela caritas. Essa compreensão trinitária, Fiore especifica da seguinte forma:

"Três são os estados do mundo que os símbolos dos textos sagrados nos prospectam. O primeiro é aquele em que vivíamos sob a lei; o segundo aquele em que vivemos sob a graça; o terceiro, cujo advento está próximo, aquele no qual viveremos em um estado de graça mais perfeito. O primeiro transcorreu na escravidão, o segundo é caracterizado por uma servidão filial, o terceiro acontecerá sob a insígnia da liberdade. $\mathrm{O}$ primeiro é marcado pelo temor, o segundo pela fé, o terceiro pela caridade. O primeiro período é aquele dos escravos, o segundo o dos filhos, o terceiro o dos amigos. [...] O primeiro estado pertence ao Pai, que é autor de todas as coisas; o segundo ao Filho, que se dignou compartilhar a nossa lama; o terceiro ao Espírito Santo, sobre o qual diz o Apóstolo: "Onde estiver o Espírito do Senhor, aí está a liberdade"" (Conc. f. 12 b-c). E ainda "Assim como o texto do Antigo Testamento, por uma certa atribuição simbólica, parece pertencer ao Pai, e o texto do Novo Testamento ao Filho, a inteligência espiritual, que brota tanto de um quanto de outro, pertence ao Espírito Santo (Exp. f. 5 b-c). ${ }^{35}$

A referência que faz Vattimo desse texto corresponde à sua compreensão acerca do período pós-moderno, concebido como período aberto pela proposta heideggeriana de evidenciar a manifestação do ser como algo que se dá, contrariando a tradicional compreensão de que o ser é, como já lembrado acima. O dar-se do ser o coloca em uma posição de Ereignis, isto é, do ser como

\footnotetext{
${ }^{33}$ VATTIMO, G., O Fim da Modernidade, p. VIII.

${ }^{34}$ HOCK, K., Introdução à ciência da religião, p. 58.

${ }^{35}$ GIOACCHINO DE FIORE apud VATTIMO, G., Depois da Cristandade, p. 43.
} 
evento/acontecimento-apropriativo em um modo em que ele se historiciza. O período da metafísica, marcado pela linguagem simbólica do antigo e do novo testamento e suas correspondências às pessoas trinitárias do Pai e do Filho, revela a permanência e a constituição do homem medieval e moderno dentro de uma cosmovisão dogmática e peremptória. Inspirado pelas proposições de Fiore, Vattimo entende que esse modelo de pensamento e de organização está superado com o advento de uma filosofia não metafísica. De modo análogo, ele relaciona a abertura desse modelo de pensamento com a chegada da Idade do Espírito Santo, que não mais se prende à letra do texto e às metanarrativas, mas é marcada pela "inteligência espiritual" capaz de interpretar as "hierofanias" 36 nas quais dá-se o ser e possibilita a abertura para um cristianismo não religioso.

De origem católica, Vattimo cresceu dentro da religião de modo ativo na pastoral juvenil de seu tempo, tendo sido leitor assíduo do "humanismo integral" de Jacques Maritain (1936). Motivado por seu percurso vital, Vattimo ingressou na Faculdade de Filosofia na Universidade de Turim, identificou-se com Nietzsche e Heidegger e passou a elaborar uma filosofia de crítica aos pressupostos metafísicos objetivistas da religião. Assim sendo, visualizou no cristianismo católico institucional posturas arbitrárias, dogmáticas em relação às questões sociais, de bioética e sexualidade, ${ }^{37}$ passando a criticar a religião católica enquanto detentora da verdade devido aos seus pressupostos demasiadamente metafísicos de cunho objetivista e autoritário. Em seu livro Credere di credere, publicado em 1996 na Itália, ${ }^{38}$ Vattimo assume essas causas como as que o fizeram abandonar o seio da Igreja Católica. No entanto, após a experiência de luto que sofreu com a morte de pessoas próximas, ele escreve:

Como o religioso "retorna" - se é que retorna, como me parece - na minha-nossa experiência atual? No que diz respeito a mim pessoalmente, não tenho vergonha de dizer que tem a ver com a experiência da morte de pessoas queridas, com as quais imaginei percorrer um trecho de estrada bem mais longo; em alguns anos, de pessoas que sempre imaginei presentes ao meu lado quando chegar a minha hora de partir e que, aliás,

\footnotetext{
${ }^{36}$ Destacamos o termo hierofanias com aspas, pois não queremos que o leitor o interprete como a manifestação do sagrado segundo a perspectiva de Otto ou de Eliade. O que se pretende, neste momento como compreensão prévia, é a noção de que a interpretação do dar-se do ser, operação que aqui chamamos de hierofania, parte primeiramente do sujeito que experiencia a faticidade (HEIDEGGER, M., Ontologia (Hermenêutica da faticidade)), algo que Vattimo entenderá como uma experiência estética.

${ }^{37}$ VATTIMO, G., Crer que se crê, p. 87.

${ }^{38}$ A edição que usamos é de tradução de Klaus Brüschke para o Brasil, sendo editado e impresso pela Editora Vozes em 2018. VATTIMO, G., Crer que se crê.
} 
me pareciam amáveis inclusive por sua virtude (afetuosa ironia para com o mundo, aceitação do limite de todo ser vivo...) de tornar a própria morte aceitável e vivível (como num verso de Höderlin: "heilend, begeisternd wie $d u$ " - sarando, inspirando, como tu). ${ }^{39}$

A afirmação de Vattimo nos remete à experiência da vida como algo único e imediato, como acontecimento-apropriativo (Ereignis) onde se situa a esfera religiosa, como experiência que imprime a marca própria do sujeito que vivencia o "evento" e exprime a si mesmo na interpretação. ${ }^{40}$ Partindo de Heidegger, também Vattimo compreende que o esquecimento do ser, embora tenha encaminhado o homem para a Ge-Stell (técnica), abriu a possibilidade de a filosofia direcionar a compreensão do ser para uma abertura, em que o respectivo horizonte não está encerrado, mas continua dinâmico e passível de interpretações mediante os múltiplos acessos possíveis a ele de acordo com a experiência de cada Dasein. Diante disso, não seria também a experiência de Deus uma experiência nessa abertura? Experiência que não se encerra na instituição, mas se coloca como princípio de um cristianismo não religioso, propiciando que se pense como se dando ou como envio relacional com quem faz a experiência religiosa. ${ }^{41}$

Devido ao enfraquecimento das estruturas não se compreende mais o sagrado como algo peremptório que se manifesta em hierofanias, mas como aquele que se revela na história mesma do sujeito pela sua simples condição de estar-no-mundo. Aqui, vale considerar que Vattimo propõe ultrapassarmos o problema da divisão entre a história sagrada e a história profana, profundamente estudada por cientistas da religião como, por exemplo, Mircea Eliade (1907-1986). Para ele, a história profana e sacra não parecem ser coisas separáveis e estão unidas em uma única história. ${ }^{42}$

O dar-se do ser na filosofia vattimiana ocasionou a sua compreensão de epocalidade do ser, condição na qual se dá sua historicidade e permite emergir o caráter hermenêutico da pós-modernidade. O ser em sua epocalidade é demitificado de qualquer pretensão objetiva de verdade e de toda estrutura forte de pensamento - para realçarmos o paralelismo com a filosofia de Vattimo sobre o pensiero debole -, propiciando espaço à ontologia hermenêutica niilista que opera no pensamento enfraquecido sem a pretensão de instituir verdade ou

\footnotetext{
${ }^{39}$ VATTIMO, G., Crer que se crê, p. 9-10.

${ }^{40}$ VATTIMO, G., A Tentação do Realismo, p. 24.

${ }^{41}$ VATTIMO, G., Depois da Cristandade, p. 58.

42 VATTIMO, G., O Fim da Modernidade, p. 61.
} 
verdades, mas sim a de compreender que a manifestação da verdade é uma valoração dialógica que prevê, sobretudo, alteridade.

\section{O Deus ornamento}

A epocalidade do ser é também marcada na filosofia de Vattimo pela sua interpretação da encarnação de Jesus Cristo. Influenciado por René Girard, ${ }^{43}$ ele compreende que o enfraquecimento das estruturas fortes "não é outra coisa senão a transcrição da doutrina cristã da encarnação do filho de Deus". ${ }^{44}$ A encarnação é dita no texto paulino ${ }^{45}$ como a kenosis de Deus, em que o Deus que se rebaixa à condição humana, saindo de sua posição transcendente e passando para uma posição imanente, que é marcada pela historização ou epocalidade. O filósofo identifica essa transcrição como secularização, assumindo uma nova compreensão da palavra, vendo-a não como contrária ao cristianismo, mas como outra face de sua identidade. ${ }^{46}$

A secularização iniciada como processo do cristianismo se assemelha com as filosofias de Nietzsche e Heidegger a respeito do diferimento da metafísica e se identifica como cume da evolução da religião cristã frente à modernidade. Isso se dá porque o anúncio primordial do cristianismo revela um Deus que não está preocupado em se localizar em uma realidade metafísica "forte", pelo contrário, é um Deus que se faz "fraco" e que vive na história dos homens. Como marca do processo de secularização está a caritas,${ }^{47}$ seu limite primordial ${ }^{48}$ pois a caritas é apelo prático e não uma condição dada metafísica ou dogmaticamente. ${ }^{49}$ A caritas, assim, é o modo pelo qual se faz possível uma relação de diálogo entre as diferentes culturas e religiões, uma vez que ela torna

${ }^{43}$ VATTIMO, G., Crer que se crê, p. 26.

${ }^{44}$ VATTIMO, G., Crer que se crê, p. 27.

45 "Dedicai-vos mutuamente a estima que se deve em Cristo Jesus. Sendo ele de condição divina, não se prevaleceu de sua igualdade com Deus, mas aniquilou-se a si mesmo, assumindo a condição de escravo e assemelhando-se aos homens. E, sendo exteriormente reconhecido como homem, humilhou-se ainda mais, tornando-se obediente até a morte, e morte de cruz" (F1 2,5-8). ${ }^{46}$ GONÇALVES, P. S. L., A evocação do pensiero debole na Teologia da Libertação, p. 252.

${ }^{47} \mathrm{O}$ termo latino caritas assume na língua portuguesa uma compreensão diferente da qual se pretende com a afirmação de Vattimo. Imprimimos no termo caridade uma relação de modo filantrópico. No entanto, Vattimo dialoga com a tradição filosófica e com a língua latina entendendo o étimo como expressão de amor ágape. Pode se dizer que caritas no latim corresponde ao ágape no grego, que é identificado como o amor divino de sublime entrega tal como entendia Agostinho.

${ }^{48}$ VATTIMO, G., Crer que se crê, p. 61-65.

${ }^{49}$ VATTIMO, G., A Idade da Interpretação, p. 71. 
expresso o limite entre as diferentes perspectivas de visão de mundo, de Weltanschauugen. ${ }^{50}$

A Idade do Espírito é herdeira da tradição que a fez emergir como uma ontologia hermenêutica niilista, que resulta no pensamento vattimiano da secularização como interpretação da própria mensagem cristã que carrega no seu bojo a caritas como expoente da revelação. Assim, a caritas é a marca da própria Idade do Espírito, época na qual a inteligência espiritual desponta como intérprete do ser que ecoa na história, tornando capaz de esta ser lida como história da salvação, que é a história da interpretação e não o contrário. Essas considerações nos apontam para um cristianismo diluído de todo dogmatismo, tornado mais "amigável" como o próprio Jesus chamou seus seguidores, de amigos. ${ }^{51}$ Há que se fazer uma reinterpretação da fé no cristianismo diante dos "sinais dos tempos", ${ }^{52}$ visando extinguir qualquer autoridade que se diga forte nos tempos atuais. Para Vattimo, a Igreja Católica é a principal vítima, pois a afirmação de verdades dogmáticas e morais sustentadas pelo Deus ontoteológico não são mais credíveis. Há de se ter um cristianismo não religioso e secularizado, com uma nova concepção de Deus. Vattimo assume a esteira da estética e propõe um Deus Ornamento, no qual há uma religião transfigurada e perpassada pela inteligência espiritual da escritura que busca, através da caritas, implantar um processo de tolerância propiciando a pluralidade das Weltanschauugen.

A estetização de Deus aqui deve trazer uma nova escatologia, não mais marcada pela passagem do homem ou sua alma ao purgatório constituído de castigos duros ou ao inferno de condenação eterna e de castigos horríveis e permanentes, mas de "fruição perfeita dos significados e das formas espirituais que a história da humanidade produziu e que constituem o reino da imortalidade". ${ }^{53}$

Vejamos que é a história da humanidade, que é, por conseguinte, a história da salvação, quem produz as significações e as formas espirituais da vida eterna e dela nós somos herdeiros, pois estamos ligados à sua tradição.

${ }^{50}$ GADAMER, H.-G., Problemas epistemológicos das ciências humanas, p. 17.

${ }^{51}$ Vattimo em diversos textos faz referência à passagem do Evangelho de João 15,15 na qual se lê: "já não vos chamo servos, mas amigos".

52 Vattimo se apropria da categoria "sinais dos tempos", desenvolvida por alguns teólogos do século XX e aproveitada no Concílio Vaticano II. Essa categoria designa os sinais históricos da presença de Deus revelada aos seres humanos, respeitando a respectiva liberdade e a condição de sujeitos de ambos os que estão envolvidos nesse encontro que a teologia denomina de revelação.

${ }^{53}$ GONÇALVES, P. S. L., A evocação do pensiero debole na Teologia da Libertação, p. 255. 
Essa concepção de um cristianismo transfigurado é o cristianismo não religioso de Vattimo que continuará guiando a história do Ocidente e imortalizando-a. A inteligência espiritual que advém dessa nova forma de fé e marco central da Idade do Espírito se volta para novas propostas políticas e éticas que envolvem um agir comunitário e superam o fundamentalismo e o relativismo religiosos, superando, com isso, as formas de violência que a imagem do sagrado inúmeras vezes suscita.

O apelo de Vattimo é o apelo de um espírito pós-moderno que entende a religião em seu retorno, não com estruturas sólidas, mas sim com uma nova perspectiva de se dar nas relações humanas. $\mathrm{O}$ aspecto religioso da pósmodernidade é algo central, uma vez que a modernidade não o tenha superado e, dessa forma, nós o carregamos como vestígio do vestígio, como convalescença, como Verwindung. ${ }^{54}$ As afirmações do filósofo turinense compreende uma perspectiva próxima da teologia de Dietrich Bonhoeffer (1906-1945), que entende que a experiência com Deus não se faz de modo "religioso", pelo ente metafísico, mas de modo dialógico com o outro, de uma forma embasada na ética cristã. A transcendência aqui é um "existir para o outro", que tem sua participação em Jesus por meio da fé. ${ }^{55}$ Vattimo pensa "na ideia de um cristianismo adulto em Dietrich Bonhoeffer, que, segundo ele [Bonhoeffer] deveria dirigir-se a Deus não mais como ao supremo deus ex machina que resolve todos os problemas e conflitos [...], mas em luta, junto com o homem, pelo triunfo do bem". ${ }^{56}$

$\mathrm{Na}$ conceituação de um Deus ornamento, a experiência religiosa é concebida sob o ponto de vista "estético", compreendido como "um estado de realidade no qual ela não mais se distingue nitidamente da fantasia: o que também chamamos de "poético". ${ }^{57} \mathrm{O}$ que se propõe pensar é que o poético, enquanto aquilo que salva - para remetermos ao Höderlin comentado pelo Heidegger (2004): "cheio de méritos, e ainda assim poeticamente, habita o homem sobre esta terra" 58 -, faz parte da vida humana na mesma dimensão de sentido. O estético é a dissolução do sagrado e do profano, do transcendente e do imanente, da fantasia e do real.

A experiência religiosa que enxerga na realidade as motivações e os frutos da espiritualidade está a caminho de uma "espiritualidade estética", capaz de

\footnotetext{
${ }^{54}$ DERRIDA, J.; VATTIMO, G., A Religião, p. 91.

${ }^{55}$ PAULY, W., Teologias do século XX, p. 233-236.

${ }^{56}$ VATTIMO, G., Crer que se crê, p. 68.

${ }^{57}$ VATTIMO, G., Depois da Cristandade, p. 70.

${ }^{58}$ VATTIMO, G., Depois da Cristandade, p. 70.
} 
superar fundamentalismos e concepções de verdades definidas em suas expressões, e de apontar uma perspectiva pós-moderna que evita reducionismos. Nesse sentido, o filósofo italiano propõe uma interpretação "espiritual" da bíblia e do mundo que se permite operar por meio do pensamento enfraquecido, abrindo-se para uma hermenêutica que leve em conta o pluralismo cultural e não sobreponha nenhuma visão de mundo à outra. Vence-se, com isso, a violência originária de pensamentos metafísicos e desconstroem-se as interpretações bíblicas que legitimem o autoritarismo, o dogmatismo e moralismo denotativos de violência nas relações humanas e sociais. Diante de uma interpretação espiritual que leva em conta o princípio da caritas, aceita-se o outro sem normatizar suas decisões, pois leva-se ao extremo o apelo prático da caritas. Nas palavras de Vattimo: "Deus é a desordem do mundo, é aquele que nos chama a não considerar como definitivo nada disto que já está aqui. Deus é projeto, e nós o encontramos, quando temos força para projetar". 59

\section{Conclusão}

Objetivamos neste artigo apresentar o modo como Deus em perspectiva cristã é pensado na pós-modernidade à luz da hermenêutica niilista de Gianni Vattimo. Justifica-se esse objetivo o fato de o filósofo italiano propiciar pensar Deus na pós-modernidade a partir da sentença nietzscheniana da "morte de Deus" e do projeto heideggeriano de "superação da metafísica", trazendo à tona uma concepção de um Deus cristão que emerge da experiência histórica da presença caritativa ou amorosa de Deus na história humana. Para atingir esse objetivo, apresentamos os conceitos de pensiero debole e pós-modernidade, formulados por Vattimo, expomos a "Idade do Espírito" como uma idade da liberdade, em que o cristianismo se liberta das amarras arbitrárias, dogmatistas e moralistas para ser um cristianismo concentrado na caritas, movimentandose em torno dela, para em seguida descrever analiticamente o "Deus ornamento", de vertente estética e teor poético, que busca explicitar a sua elevação desde a elevação do humanum.

Gianni Vattimo levou a cabo a unidade da sentença da "morte de Deus" e do projeto da "superação da metafísica", formulando a sua hermenêutica niilista para romper com formas autoritárias de religião e sociedade, e para apresentar um caminho para o desenvolvimento da liberdade humana. Para isso, aproveitou-se de sua formação cristã e filosófica e elaborou o seu "cristianismo não religioso" para trazer à tona um cristianismo que se torna um status

${ }^{59}$ VATTIMO, G., Deus é projeto e nós o encontramos quando temos força para projetar, p. 11. 
spiritualis na forma de conviver de toda a humanidade. Desse modo, Deus não é uma figura violenta emergente de uma metafísica objetivista que incide na vida humana em forma de autoritarismos religiosos e sociais, de dogmatismos e moralismos que impedem o exercício da liberdade humana. Trata-se de um Deus que não se reduz a proposições conceituais, que não impõe medo ao ser humano, mas que interpela o ser humano ao diálogo, estimula a prática ecumênica, o diálogo inter-religioso, o comunitarismo, o respeito, o acolhimento à "outrididade" diferente, possibilitando a convivência fraterna entre os seres humanos.

Um Deus pensado na perspectiva de um cristianismo não religioso, conforme a formulação vattimiana, provém depois do "Deus da metafísica objetivista", pois é amigo dos seres humanos. Trata-se de um "Deus ornamento", porque sua Beleza conduz à realização da beleza humana, sempre elevada pela poesia e por uma estética que aponta a glória divina desde a glória dos seres humanos, concebidos na plenitude da vida, marcada pela fraternidade, justiça e paz.

\section{Referências bibliográficas}

BAUMAN, Z. O mal-estar da pós-modernidade. Rio de Janeiro: Zahar, 1998.

DE LUBAC, H. O drama do humanismo ateu. Itapevi/SP: Nebli, 2015.

DERRIDA, J.; VATTIMO, G. A Religião. O Seminário de Capri. São Paulo: Estação Liberdade, 2000.

EAGLETON, T. The usion of postmodernism. Oxford (England): Blackwell Publishers, 1996.

GADAMER, H.-G. Problemas epistemológicos das ciências humanas. In.: FRUCHON, P. (Org.). O problema da consciência histórica. Rio de Janeiro: Editora FGV, 2003. p. 17-25.

GIDDENS, A. As consequências da modernidade. São Paulo, Unesp, 1991.

GONÇALVES, P. S. L. A evocação do pensiero debole na Teologia da Libertação. Interações, v. 13, n. 24, p. 391-413, ago./dez. 2018 a.

HEGEL, G. W. F. Fenomenologia do Espírito. Petrópolis/RJ: Vozes, 1992. v. 1. HEIDEGGER, M. Ontologia (Hermenêutica da faticidade). 2.ed. Petrópolis/RJ: Vozes, 2013. 
HEIDEGGER, M. Wegmarken. Frankfurt am Main: Vittorio Klostermann, 1976. HERRERA, J. A. R. Supuestos kenóticos del pensamento débil. A Parte Rei, n. 54, p. 1-5, 2007.

HOCK, K. Introdução à ciência da religião. São Paulo: Loyola, 2010.

LIMA VAZ, H. C. Antropologia Filosófica. São Paulo: Loyola, 2014. v. 1.

LIPOVETSKY, G. Tempo contra tempo, ou a sociedade hipermoderna. In: CHARLES, S.; LIPOVETSKY, G. Os Tempos Hipermodernos. São Paulo: Barcarolla, 2004. p. 49-103.

NIETZSCHE, F. W. Pere 1882/1895. Roma: Grandi Tascabili Economici Newton, 1993.

PAULY, W. Teologias do século XX. In: PAULY, W. (Org.). História da teologia cristã. São Paulo: Loyola, 2012. p. 227-266.

PECORARO, R. Niilismo e Pós-modernidade: Introdução ao pensamento fraco de Gianni Vattimo. São Paulo: Loyola, 2005.

ROTTERDAN, S.; SENRA, F. O cristianismo não religioso de Gianni Vattimo: considerações para o senso religioso contemporâneo. Religare, v. 12, n. 1, p. 96-127, jun. 2015.

TEIXEIRA, E. Pós-modernidade e niilismo - um diálogo com Gianni Vattimo. Alceu, v. 7, n. 13, p. 209-224, jul./dez. 2006.

VATTIMO, G. O Fim da Modernidade: niilismo e hermenêutica na cultura pós-moderna. São Paulo: Martins Fontes, 2002.

VATTIMO, G. A Sociedade Transparente. Lisboa: Relógio-d'água, 1992.

VATTIMO, G. Crer que se crê: é possível ser cristão apesar da Igreja?. Petrópolis/RJ: Vozes, 2018.

VATTIMO, G. Diálogos com Nietzsche. São Paulo: Martins Fontes, 2010.

VATTIMO, G. A Tentação do Realismo. Rio de Janeiro: Lacerda Ed.: Istituto Italiano di Cultura, 2001.

VATTIMO, G. Depois da Cristandade: por um cristianismo não religioso. Rio de Janeiro: Record, 2004. 
VATTIMO, G. Deus é projeto e nós o encontramos quando temos força para projetar [Entrevista concedida a IHU-Online]. IHU-Online, v. 128, p. 10-13, dez. 2004.

VATTIMO, G. A Idade da Interpretação. In.: ZABALA, S. (Org.). O futuro da religião: solidariedade, caridade e ironia. Rio de Janeiro: Relume Dumará, 2006. p. 63-76.

VATTIMO, G. O vestígio do vestígio. In: DERRIDA, J.; VATTIMO, G. A Religião. O Seminário de Capri. São Paulo: Estação Liberdade, 2000. p. 91-107.

VATTIMO, G. Para Além Da Interpretação: o Significado Da Hermenêutica Para A Filosofia. [s.l.]: Tempo Brasileiro, 1999.

\section{Paulo Sérgio Lopes Gonçalves}

Doutor em Teologia pela Pontificia Università Gregoriana Docente no Programa de Pós-graduação em Ciências da Religião da Pontifícia Universidade Católica de Campinas Campinas / SP - Brasil E-mail: p_aselogo@puc-campinas.edu.br

Felipe de Queiroz Souto Doutorando em Ciência da Religião pela UFJF com bolsa CAPES Discente do curso de Especialização em Metafísica e Epistemologia da UFCA

Juiz de Fora / MG - Brasil E-mail: felipeqsouto@gmail.com

Recebido em: 18/02/2021

Aprovado em: 15/12/2021 